\title{
Overexpression of malignant brain tumor domain containing protein 1 predicts a poor prognosis of prostate cancer
}

\author{
WANHUA WU ${ }^{1,2^{*}}$, SHOUMIN BAI $^{*}$, DINGJUN ZHU ${ }^{1,2^{*}}$, KAIWEN LI $^{1,2}$, \\ WEN DONG ${ }^{1,2}$, WANG HE ${ }^{1,2}$, SHENGMENG PENG ${ }^{1,2}$, YIMING LAI ${ }^{1,2}$, QIONG WANG ${ }^{1,2}$, \\ ZHENGHUI GUO ${ }^{1,2}$, LEYUAN LIU ${ }^{3,4}$ and HAI HUANG ${ }^{1-3}$ \\ ${ }^{1}$ Department of Urology; ${ }^{2}$ Guangdong Provincial Key Laboratory of Malignant Tumor Epigenetics and Gene Regulation, \\ The Sun Yat-Sen Memorial Hospital, Sun Yat-Sen University, Guangzhou, Guangdong 510120, P.R. China; \\ ${ }^{3}$ Institute of Biosciences and Technology, Texas A\&M Health Science Center, Houston, TX 77030; \\ ${ }^{4}$ Department of Molecular and Cellular Medicine, College of Medicine, Texas A\&M University, College Station, TX 77845, USA
}

Received March 10, 2018; Accepted October 29, 2018

DOI: $10.3892 /$ ol.2019.10109

\begin{abstract}
Malignant brain tumor domain containing protein 1 (MBTD1) is a member of the polycomb group protein family that is associated with tumorigenesis. The present study investigated the role of MBTD1 within defined clinicopathological parameters and the prognosis of patients with prostate cancer ( $\mathrm{PCa}$ ). A human tissue microarray containing samples from 71 patients with $\mathrm{PCa}$ and seven healthy donors was employed for immunohistochemistry (IHC). The clinicopathological characteristics and prognostic value of MBTD1 were investigated using a dataset of 499 patients from The Cancer Genome Atlas (TCGA). IHC illustrated that the levels of MBTD1 protein were enhanced and markedly associated with aggressive clinical stage and advanced tumor invasion, distant metastasis and lymph node metastasis in patients with PCa. In the TCGA data set, the level of MBTD1 was found to positively correlate with the prostate-specific antigen level, Gleason score and distant
\end{abstract}

Correspondence to: Professor Hai Huang, Department of Urology, The Sun Yat-Sen Memorial Hospital, Sun Yat-Sen University, 107 West Yanjiang Road, Guangzhou, Guangdong 510120, P.R. China E-mail: huanghai257@126.com

Professor Leyuan Liu, Institute of Biosciences and Technology, TX A\&M Health Science Center, 2121 West Holcombe Boulevard, Houston, TX 77030, USA

E-mail: 1liu@ibt.tamhsc.edu

*Contributed equally

Abbreviations: BCR, biochemical recurrence; IHC, immunohistochemistry; MBTD1, malignant brain tumor domain containing protein $1 ; \mathrm{PCa}$, prostate cancer; $\mathrm{PcG}$, polycomb group of genes; PSA, prostate-specific antigen; TCGA, The Cancer Genome Atlas; TMA, tissue microarray

Key words: MBTD1, metastasis, prognosis, prostate carcinoma, survival metastasis. The multivariate analysis of Cox regression revealed that the levels of MBTD1 may act as an independent prognostic factor for low non-biochemical, recurrence-free survival. In conclusion, MBTD1 was overexpressed in PCa tissues and is associated with aggressive clinicopathological characteristics. It may therefore act as a novel prognostic factor and diagnostic marker in PCa.

\section{Introduction}

Since the 1990s, the incidence of prostate cancer (PCa) has increased considerably due to population growth, increased age expectancy and prevalent prostate-specific antigen (PSA) screening (1). Active surveillance may effectively manage patients with low-risk PCa $(2,3)$ while those suffering from aggressive $\mathrm{PCa}$ require efficient intervention to reduce the development of advanced disease and PCa-associated mortality (4,5). Therefore, distinguishing low-risk disease from more aggressive forms of $\mathrm{PCa}$, and subsequently reducing the rate of overtreatment, is of great clinical relevance. At present, various combinations of PSA, Gleason score, tumor, node, metastasis stage, and surgical margin are used as prognosis predictors $(6,7)$. The use of PSA screening not only reduces the development of advanced and metastatic PCa and PCa-associated mortality, but also assists in the detection of indolent PCa and consequential overtreatment (5). Therefore, determining the molecular mechanisms of aggressive and indolent $\mathrm{PCa}$ and investigating novel prognostic biomarkers to predict clinical outcome is crucial.

The polycomb group $(\mathrm{PcG})$ regulates transcription through nucleosome modification and chromatin remodeling, and interacts with other transcription factors (8). Malignant brain tumor domain containing protein 1 (MBTD1), encoded by the MBTD1 gene on chromosome $17 \mathrm{q} 21.33$ is one such $\mathrm{PcG}$ protein, consisting of 628 amino acids and four malignant brain tumor (MBT) repeats (9). The MBT repeat is a structural motif of 100 amino acids conserved from Caenorhabditis elegans, and originally discovered in Drosophila as L(3)MBT. L(3)MBT mutations cause neoplastic translations of optic neuroblasts (10). The PcG proteins have been recognized for 
their role in tumorigenesis (8). MBTD1 has been reported to be a subunit of the histone acetyltransferase TIP60/ ${ }_{\mathrm{NuA} 4}$ acetyltransferase complex, which promotes the repair of DNA double-strand breaks through homologous recombination (11). Mutations in MBTD1 have been identified in endometrial stromal sarcoma and leukemia (12-14). Other MBT repeat proteins have been reported to control the transcriptional state of chromatin regions $(15,16)$. However, the role of MBTD1 in $\mathrm{PCa}$ is yet to be ascertained. Therefore, the present study investigated the expression of MBTD1 in PCa to determine the association between expression levels of MBTD1, clinicopathological characteristics and PCa prognosis.

\section{Materials and methods}

Patients and tissue samples. A total of $71 \mathrm{PCa}$ tissues were selected, along with three adjacent and four normal prostate tissues, from a tissue microarray (TMA) (Xi'an Alenabio Co., Ltd. Xi'an, China; no. PR803c), and the clinical characteristics were assessed using IHC analysis. Patients who had undergone radiotherapy or chemotherapy prior to surgery were excluded. The clinical parameters, from The Cancer Genome Atlas (TCGA) database, of 499 PCa tissues and 52 normal prostate tissues were collected to study the expression level of MBTD1, and to perform survival analysis. The clinical characteristics of all patients are summarized in Table I.

IHC analysis. The tissue microarray (Xi'an Alenabio Co., Ltd.) was used in IHC analysis. Specimens were fixed in $10 \%$ neutral-buffered formalin solution overnight at room temperature and embedded in paraffin. The paraffin-embedded tissues were then cut into $4 \mu \mathrm{m}$-thick slices. The tissue slices were subsequently deparaffinized by immersing in xylene and rehydrated using a graded ethanol series at room temperature. The tissues were washed in PBS and distilled water for further peroxidase (3'-diaminobenzidine) IHC staining using the DAKO EnVision System (Dako; Agilent Technologies, Inc., Santa Clara, CA, USA). Following proteolytic digestion with peroxidase with $0.01 \mathrm{M}$ citrate (catalog no. AR0024; Boster Biological Technology, Pleasanton, CA, USA) in a microwave for $\sim 6$ min, blocking was performed with goat serum (catalog no. KIT-0305; MX Biotechnologies, Fuzhou, China) at room temperature for $30 \mathrm{~min}$. IHC staining was conducted using the UltraSensitive ${ }^{\mathrm{TM}}$ SP (Mouse/Rabbit) IHC kit (catalog no. KIT-0305; MX Biotechnologies), which contained endogenous peroxidase blocking solution, serum, secondary antibody, streptavidin-perosidase and substrate-chromogen. The tissues sections were incubated overnight at $4^{\circ} \mathrm{C}$ with a rabbit anti-human polyclonal antibody against MBTD1 (cat. no. ab170848; Abcam, Cambridge, UK), at a dilution of 1:80. Following washing, the sections were incubated with an avidin-conjugated secondary antibody (catalog no. KIT-0305; MX Biotechnologies, Fuzhou) for $30 \mathrm{~min}$ at room temperature. Streptavidin-peroxidase $(50 \mu \mathrm{l}$ for $15 \mathrm{~min}$ at room temperature) and substrate-chromogen (100 $\mu \mathrm{l}$ for $2 \mathrm{~min}$ at room temperature) were used to observe the staining of the target protein. For negative controls, the primary antibody was omitted in each IHC run (17).

Evaluation of immunostaining results. The intensity of immunostaining was scored by two experienced pathologists with no prior knowledge of the clinical and pathological details of the patients. The scores were compared, and any conflict was reevaluated by regrading of the immunostaining by the same pathologists. A total of five representative fields were microscopically observed (magnification, x400) and the number of positively-stained cells was enumerated. Cytoplasmic and nuclear staining was regarded as positive according to the antibody specification sheet (18). The expression level of MBTD1 in each sample was semi quantitatively scored depending on the staining intensity and percentage of stained cells. The staining intensity was classified based on the following criteria: None (0), mild (1), moderate (2) and strong (3). The percentage of positive cells was stratified as follows: $<5 \%(0)$, $6-25 \%$ (1), $26-50 \%$ (2), $51-75 \%$ (3) and $>75 \%$ (4). The final immunoreactivity scores (IRS) were calculated by adding the immunostaining percentages and immunostaining intensity scores. Using the median score as the cutoff point, an IRS $\geq 4$ and $<4$ was defined as high and low expression, respectively $(19,20)$.

Assays of protein expression of MBTDl in cell lines. PCa cells 22RV1, LNCap, DU-145, PC3 and the benign prostatic hyperplasia epithelial cell line (BPH1) were obtained from the Center of Experiment Animal of Sun Yat-sen University (Guangzhou, China). The cells were cultured in a humidified $\mathrm{CO}_{2}$ incubator at $37^{\circ} \mathrm{C}$ with RPMI 1640 medium (Gibco; Thermo Fisher Scientific, Inc., Waltham, MA, USA) supplemented with $10 \%$ fetal bovine serum and $1 \%$ penicillin-streptomycin (both from Invitrogen; Thermo Fisher Scientific, Inc.), The cell lines were used to assess the protein expression level of MBTD1. A total of $1 \times 10^{7}$ cells/sample were washed twice using PBS, prior to lysis using radioimmunoprecipitation buffer (Beyotime Institute of Biotechnology, Haimen, China) for $30 \mathrm{~min}$, and subsequently centrifuged at $17,225.6 \mathrm{x}$ g for $30 \mathrm{~min}$ at $4^{\circ} \mathrm{C}$. A bicinchoninic acid assay kit was employed to measure the total protein concentration of each extract. The proteins were transferred to a PVDF membrane (EMD Millipore, Billerica, MA, USA) following $10 \%$ SDS-PAGE separation with $20 \mu \mathrm{g}$ protein per lane. The membranes were blocked using 5\% nonfat dry milk for $1 \mathrm{~h}$ in TBS with Tween-20 (TBST) at room temperature and subsequently probed with rabbit anti-human polyclonal antibody against MBTD1 (cat. no. ab170848; 1:500; Abcam) and $\beta$-actin (cat. no. BM0627; 1:4,000; Boster Biological Technology) overnight at $4^{\circ} \mathrm{C}$. After washing three times with TBST, the membrane was incubated with horseradish peroxidase-conjugated secondary antibody (cat. no. BA1054; 1:5,000; Boster Biological Technology) for a further $2 \mathrm{~h}$. Finally, the protein bands were detected using a Chemiluminescence imaging analysis system (catalog no. 5200; Tanon Science and Technology Co., Ltd., Tokyo, Japan). The relative density of protein expression was quantified using Image J 1.8.0 software (National Institutes of Health, Bethesda, MD, USA) (21).

Statistical analysis. SPSS 22.0 software (IBM Corp., Armonk, NY, USA) was used for statistical analysis. Patient characteristics are presented as counts and percentages for categorical data, and mean \pm standard deviation for continuous data. Fisher's exact test and Pearson's $\chi^{2}$ tests were employed to evaluate the correlation between MBTD1 expression levels and clinicopathological parameters. For 
Table I. Correlation of MBTD1 expression with clinicopathologic characteristics in patients with prostate cancer.

\begin{tabular}{|c|c|c|c|c|c|c|c|}
\hline \multirow{2}{*}{$\begin{array}{l}\text { Clinical } \\
\text { features }\end{array}$} & \multicolumn{4}{|c|}{ TMA } & \multicolumn{3}{|c|}{ TCGA } \\
\hline & Case & Low, n (\%) & High, n (\%) & P-value & Case & $\bar{x} \pm \mathrm{S}$ & P-value \\
\hline \multicolumn{8}{|l|}{ Tissue } \\
\hline Cancer & 71 & $32(45.1)$ & $39(54.9)$ & \multirow{2}{*}{$0.006^{\mathrm{b}}$} & 499 & $520.20 \pm 8.31$ & \multirow{2}{*}{$<0.001^{\mathrm{b}}$} \\
\hline Benign & 7 & $7(100.0)$ & $0(0.0)$ & & 52 & $448.3 \pm 15.21$ & \\
\hline \multicolumn{8}{|c|}{ Age, years } \\
\hline$<60$ & 12 & $7(58.3)$ & $5(41.7)$ & \multirow[t]{2}{*}{0.536} & $201(<60)$ & $533.67 \pm 209.88$ & \multirow[t]{2}{*}{0.189} \\
\hline$\geq 60$ & 66 & $32(48.5)$ & $34(51.5)$ & & $296(\geq 60)$ & $511.38 \pm 166.72$ & \\
\hline \multicolumn{8}{|c|}{ PSA level } \\
\hline$\leq 4$ & - & - & - & \multirow[t]{2}{*}{-} & 413 & $520.59 \pm 179.19$ & \multirow[t]{2}{*}{$0.023^{\mathrm{a}}$} \\
\hline$>4$ & - & - & - & & 27 & $605.62 \pm 289.09$ & \\
\hline \multicolumn{8}{|c|}{ Gleason score } \\
\hline$\leq 7$ & - & - & - & \multirow[t]{2}{*}{-} & 291 & $502.56 \pm 178.27$ & \multirow[t]{2}{*}{$0.011^{\mathrm{a}}$} \\
\hline$>7$ & - & - & - & & 206 & $545.60 \pm 192.93$ & \\
\hline \multicolumn{8}{|c|}{ Pathological grade } \\
\hline$\leq 2$ & 23 & $9(39.1)$ & $14(60.9)$ & \multirow[t]{2}{*}{0.397} & - & - & \multirow[t]{2}{*}{ - } \\
\hline$>2$ & 44 & $22(50.0)$ & $22(50.0)$ & & - & - & \\
\hline \multicolumn{8}{|c|}{ Clinical stage } \\
\hline I-II & 44 & $26(59.1)$ & $21(40.9)$ & \multirow[t]{2}{*}{$0.003^{\mathrm{b}}$} & - & - & \multirow[t]{2}{*}{ - } \\
\hline III-IV & 26 & $6(23.1)$ & $20(76.9)$ & & - & - & \\
\hline \multicolumn{8}{|c|}{ Tumor invasion } \\
\hline $\mathrm{T} 1-\mathrm{T} 2$ & 46 & $26(56.5)$ & $20(43.5)$ & \multirow[t]{2}{*}{$0.012^{\mathrm{a}}$} & 351 & $497.24 \pm 171.27$ & \multirow[t]{2}{*}{0.110} \\
\hline T3-T4 & 24 & $6(25.0)$ & $18(75.0)$ & & 55 & $556.07 \pm 260.38$ & \\
\hline \multicolumn{8}{|c|}{ Lymph node metastasis } \\
\hline No & 58 & $30(51.7)$ & $28(48.3)$ & \multirow[t]{2}{*}{$0.026^{\mathrm{a}}$} & 344 & $520.81 \pm 181.97$ & \multirow[t]{2}{*}{0.307} \\
\hline N1 & 12 & $2(16.7)$ & $10(83.3)$ & & 80 & $543.69 \pm 172.95$ & \\
\hline \multicolumn{8}{|c|}{ Distant metastasis } \\
\hline M0 & 56 & $29(51.8)$ & $27(48.2)$ & \multirow[t]{2}{*}{$0.039^{\mathrm{a}}$} & 455 & $517.20 \pm 178.44$ & \multirow[t]{2}{*}{$<0.001^{\mathrm{b}}$} \\
\hline M1 & 14 & $3(21.4)$ & $11(78.6)$ & & 3 & $1041.11 \pm 691.26$ & \\
\hline
\end{tabular}

'-' indicates a lack of the relevant information for patients in the cohort. ${ }^{\mathrm{a}} \mathrm{P}<0.05,{ }^{\mathrm{b}} \mathrm{P}<0.01$. $\mathrm{x} \pm \mathrm{s}$, mean \pm standard deviation; MBTD1, malignant brain tumor domain-containing protein 1; PSA, prostate-specific antigen; TCGA, The Cancer Genome Atlas database.

independent samples, Student's t-tests for normally distributed data or the Mann-Whitney U test for non-normally distributed data were employed to evaluate continuous data. Analysis of variance was employed in the quantification analysis of western blots (Fig. 1H). The overall survival was analyzed using the Kaplan-Meier method and the differences were evaluated using the log-rank test (22). The Cox proportional hazards regression model was employed for univariate analysis comparisons and multivariate survival comparisons. The corresponding 95\% confidence interval and the adjusted hazard ratios (HRs) were used to represent the relative risk of mortality. $\mathrm{P}<0.05$ was considered to indicate a statistically significant difference.

\section{Results}

Overexpression of MBTD1 protein in human PCa tissues and cell lines and its association with clinicopathological features. First, the IHC analysis was preformed to evaluate the expression level of MBTD1 in 71 PCa tissues and three adjacent normal and four normal prostate tissues (Table I). As presented in Fig. 1A-F, a strong MBTD1 immunostaining signal was present in the cytoplasm of PCa cells, while normal tissues stained weakly. The expression of MBTD1 was significantly higher in PCa tissues compared with normal tissues (Fig. 1B). The expression of MBTD1 protein was high in $39(54.9 \%)$ patients and low in $32(45.1 \%)$ patients out of the 71 patients with $\mathrm{PCa}$. Analysis of the association between MBTD1 levels and clinicopathological characteristics of PCa demonstrated that the expression level of MBTD1 was significantly correlated with aggressive clinical stage, tumor invasion, lymph node metastasis, and advanced distant metastasis, while the expression level of MBTD1 was not associated with age and pathological grade (Table I). Furthermore, western blot analysis indicated that the expression level of MBTD1 in PCa cells, 22RV1, LNCap, DU-145 and PC3, was significantly 
A

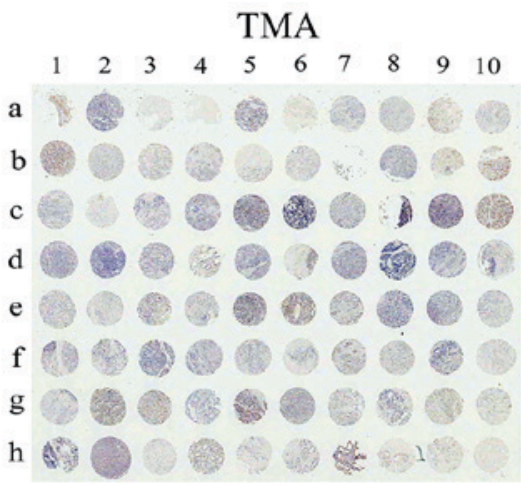

C

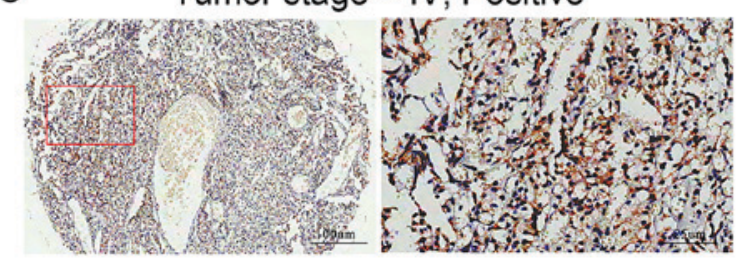

E

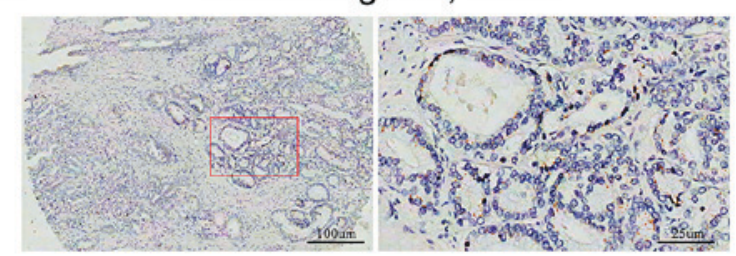

G

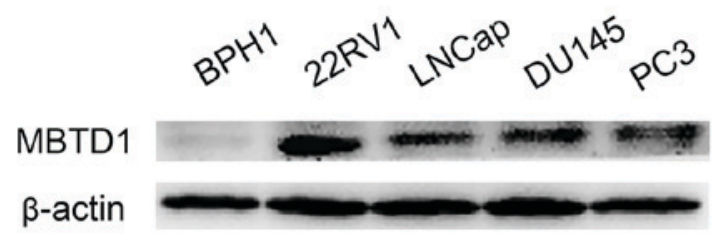

B

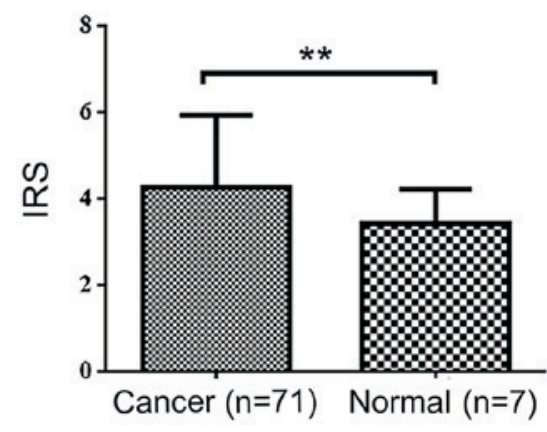

D

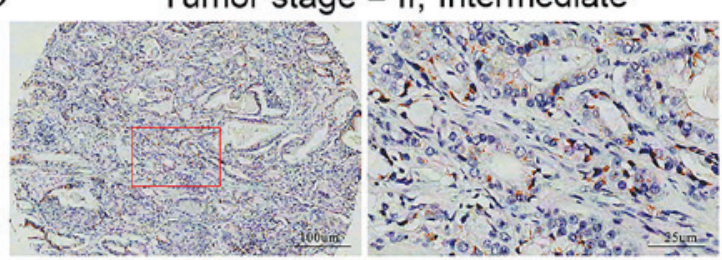

F Normal prostatic tissue, Weak

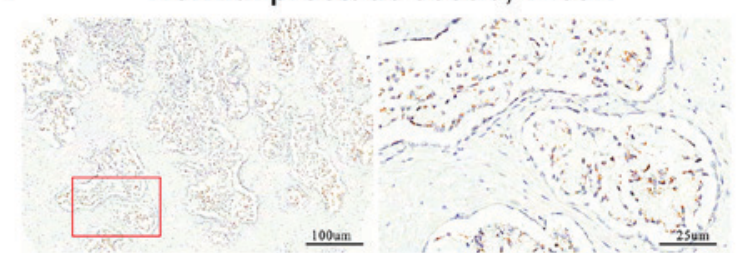

$\mathrm{H}$

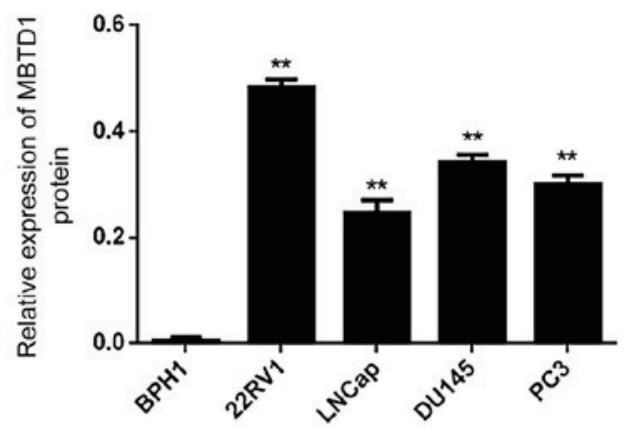

Figure 1. Overexpression of MBTD1 in PCa tissues and cell lines. (A) IHC staining of MBTD1 in the tissue microarray cohort. (B) The differences in immunoreactivity scores of MBTD1 between PCa tissues and normal prostate tissues. ${ }^{* *} \mathrm{P}<0.01$. IHC staining of the distribution of MBTD1 in the cytoplasm of PCa and the different intensities of MBTD1 designated (C) positive, (D) intermediate and (E) weak. (F) Weak staining of MBTD1 in normal prostate tissues. The magnification in the left and right panels is $\mathrm{x} 40$ and $\mathrm{x} 200$, respectively. Representative $(\mathrm{G})$ western blots and (H) quantification of the expression of MBTD1 protein in 22RV1, LNCap, DU-145, PC3 and BPH1 cell lines. ${ }^{* *} \mathrm{P}<0.01$ vs. BPH1. PCa, prostate cancer; MBTD1, malignant brain tumor domain containing protein 1 ; IHC, immunohistochemistry.

higher compared with that in benign prostatic hyperplasia BPH1 cells (Fig. $1 \mathrm{G}$ and $\mathrm{H}$ ).

Correlation between overexpression of MBTD1, enhanced progression and poor prognosis of $P C a$ in human patients, as documented in the TCGA database. To further confirm the results of the TMA, the MBTD1 mRNA expression levels of 499 PCa tissues and 52 normal prostate tissues deposited in the TCGA dataset were investigated. In PCa tissues, the expression levels of MBTD1 mRNA were upregulated and positively correlated with PSA levels, Gleason score, and distant metastasis, but not with age, tumor invasion, and lymph node metastasis (Table I).

The Kaplan-Meier method was used to analyze the association between the expression of MBTD1 and the survival time of patients with $\mathrm{PCa}$. Improved biochemical recurrence (BCR)-free survival and overall survival were presented in patients with low expression level of MBTD1 (Fig. 2A and B). Among non-metastatic patients, low expression of MBTD1 was associated with longer BCR-free survival (Fig. 2C and D).

MBTD1 is an independent prognostic factor for the survival of patients with PCa. The Cox proportional hazards model was applied to assess whether MBTD1 acted as an independent prognostic factor for PCa survival in the TCGA dataset. The expression of MBTD1 correlated with BCR-free survival in patients with PCa with an HR of 1.884. The PSA level, Gleason score, tumor invasion and lymph node stage exhibited the same trends, as demonstrated by univariate analysis (Table II). Multivariate analysis with the Cox proportional hazards model 
A

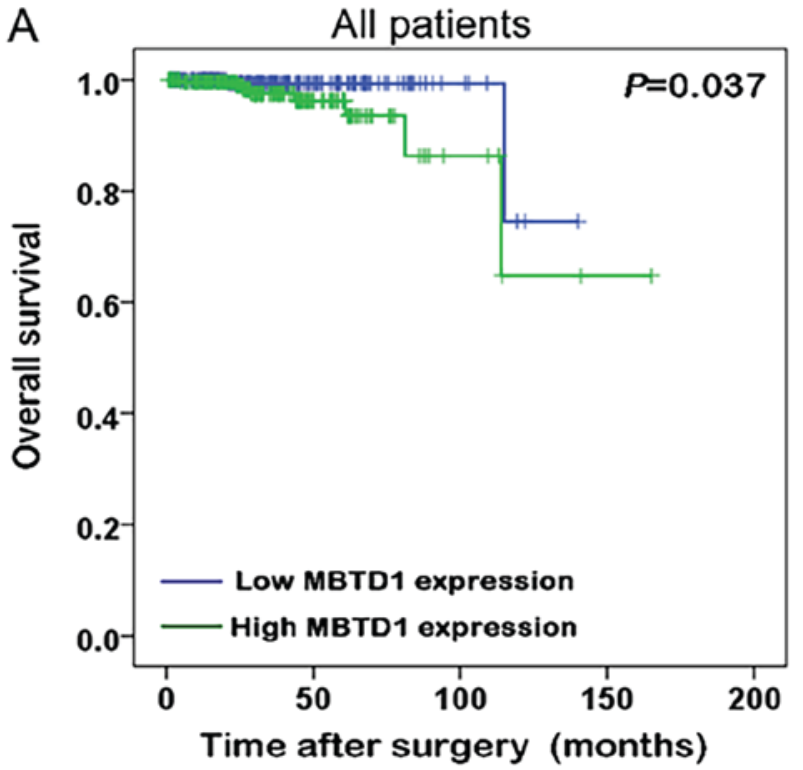

C Non-metastatic patients

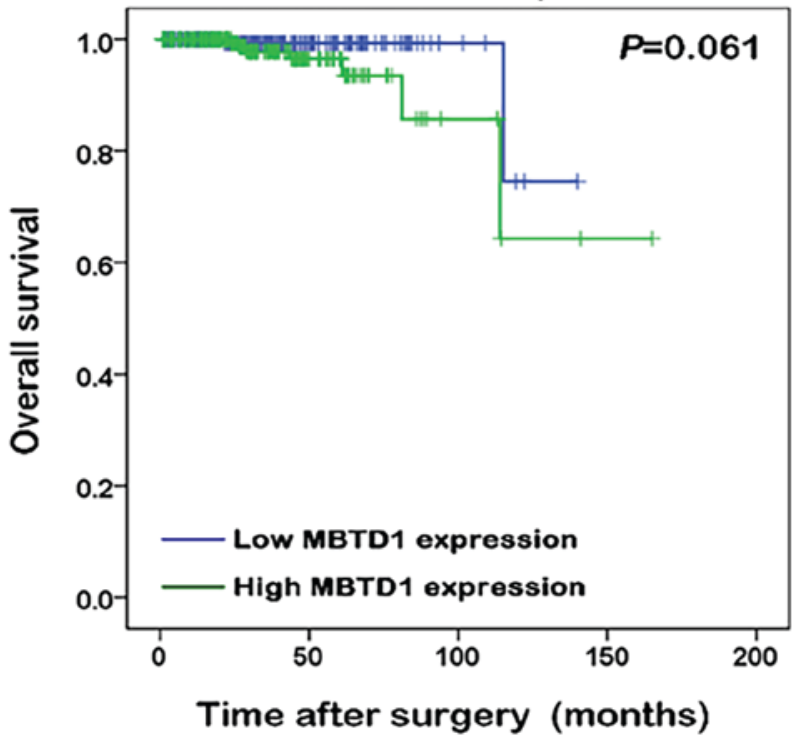

B

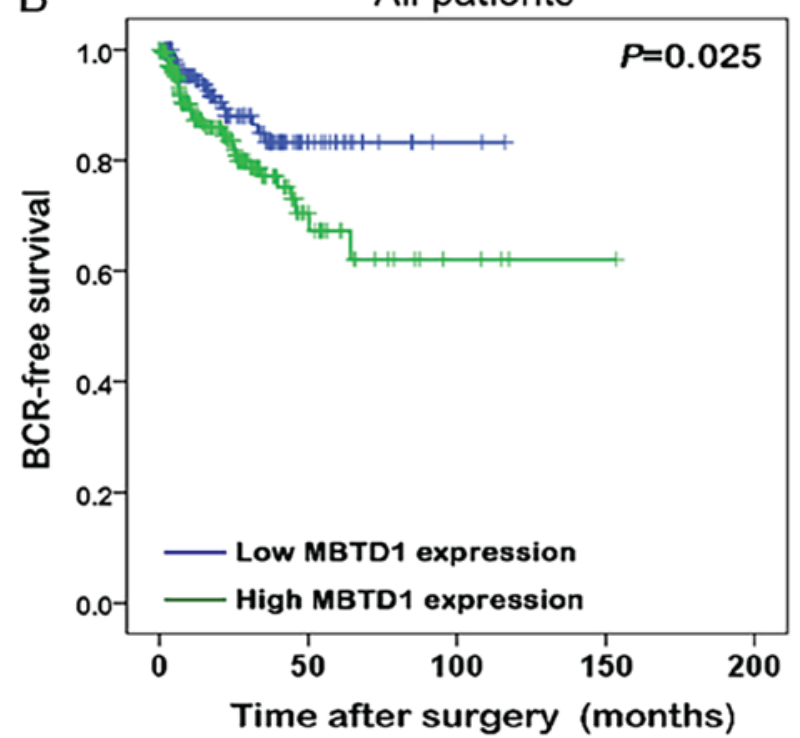

D

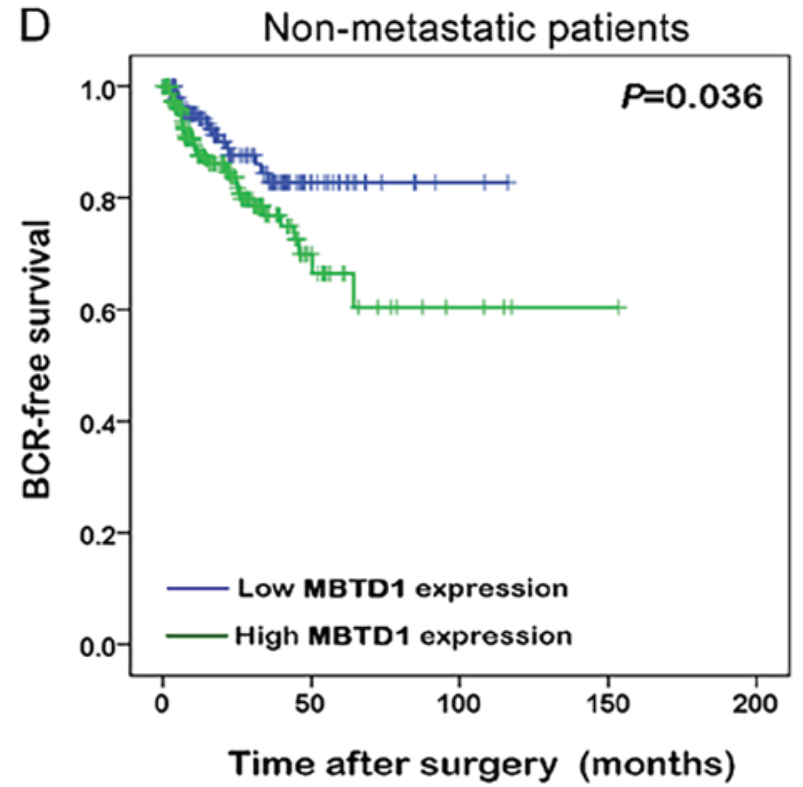

Figure 2. Overexpression of malignant brain tumor domain containing protein 1 predicts a poor prognosis of patients with prostate cancer. Differences in the (A) overall survival and (B) BCR-free survival between high and low expression levels of MBTD1 using Kaplan-Meier survival analyses. Kaplan-Meier survival analyses showing the difference in (C) overall survival and (D) BCR-free survival between high and low expression levels of MBTD1 in non-metastatic patients. MBTD1, malignant brain tumor domain containing protein 1; BCR, biochemical recurrence.

was employed to confirm that the MBTD1 level acted as a significant factor for PCa (Table II).

\section{Discussion}

Although the diagnostic and treatment methodologies for $\mathrm{PCa}$ have advanced, and the survival rate has increased, efficient risk attribution and prognosis prediction of $\mathrm{PCa}$ remains a crucial issue. Discovering novel biomarkers to predict recurrence and metastatic potential may aid patient management and decrease the morbidity associated with $\mathrm{PCa}$. In the present study, MBTD1 was overexpressed in PCa tissues and was significantly associated with the advanced clinicopathological characteristics of PCa. Furthermore, MBTD1 was recognized as an independent prognostic factor in $\mathrm{PCa}$, and higher expression of MBTD1 predicted poorer BCR-free survival.

The role of $\mathrm{PcG}$ as an oncogenic factor has been confirmed (8), and is consistent with the findings of the present study, that MBTD1 was overexpressed in PCa tissues. Like other PcG proteins, MBTD1 may regulate the transcription of developmentally-associated genes through chromatin remodeling, nucleosome modification and interaction with other transcription factors $(8,9)$. It interrupts signaling pathways that govern cellular behavior, reduces the activity of tumor suppressors, activates proto-oncogenes and ultimately influences tumorigenesis. The present study demonstrated that the overexpression of MBTD1 was associated with progressive disease and consequently, poor prognosis and shorter patient survival time. 
Table II. Prognostic value of MBTD1 expression for BCR-free survival revealed by Cox proportional hazards model.

A, Univariate analysis

\begin{tabular}{lrr}
\hline & & BCR-free survival \\
\cline { 2 - 3 } Variable & HR (95\%CI) & 0.310 \\
\hline Age ( $\geq 60$ vs. $<60)$ & $1.319(0.773-2.250)$ & $<0.001^{\mathrm{b}}$ \\
PSA level (>4 vs. $\leq 4)$ & $10.426(5.309-20.474)$ & $<0.001^{\mathrm{b}}$ \\
Gleason score (<7 vs. 7 vs. $>7)$ & $3.175(1.881-5.360)$ & 0.199 \\
Clinical stage (I vs. II vs. III vs. IV) & $1.451(0.822-2.559)$ & $<0.001^{\mathrm{b}}$ \\
Tumor invasion (T1-T2 vs. T3-T4) & $3.950(2.226-7.008)$ & $0.034^{\mathrm{a}}$ \\
Lymph node metastasis (N0 vs. N1) & $1.879(1.049-3.365)$ & 0.212 \\
Distant metastasis (M0 vs. M1) & $3.536(0.488-25.641)$ & $0.028^{\mathrm{a}}$ \\
MBTD1 expression (low vs. high) & $1.884(1.072-3.312)$ & \\
\hline
\end{tabular}

B, Multivariate analysis

\begin{tabular}{lrr}
\hline & & BCR-free survival \\
\cline { 2 - 3 } Variable & HR (95\%CI) & P-value \\
\hline Age ( $\geq 60$ vs. <60) & $1.193(0.683-2.085)$ & 0.536 \\
Lymph node metastasis (N0 vs. N1) & $1.716(0.951-3.098)$ & 0.073 \\
MBTD1 expression (low vs. high) & $1.840(1.007-3.362)$ & $0.047^{\mathrm{a}}$ \\
\hline
\end{tabular}

${ }^{\mathrm{a}} \mathrm{P}<0.05,{ }^{\mathrm{b}} \mathrm{P}<0.01$. HR, hazard ratio; CI, confidence interval; MBTD1, malignant brain tumor domain-containing protein 1.

The mechanisms underlying the contribution of MBTD1 to the progression of PCa are elusive and complex. MBTD1 acts as a subunit of the NuA4/TIP60 acetyltransferase complex $(9,23)$ and allows TIP60 to interact with specific promoters for the activation of homologous recombination (via histone reader domain H4K20me1/2) (11). In malignant tumor cells, the DNA damage repair system is usually upregulated to provide the optimal environment for cell proliferation and survival. Defects in this system are associated with the sensitivity of chemotherapy drugs in tumor cells and considered as targets for tumor therapy $(24,25)$. The overexpression of MBTD1 in PCa may be associated with the upregulation of DNA damage repair and consequently, with poor prognosis (26). Since PcG proteins have been recognized as candidates for targeted therapy (27), MBTD1 may also serve as a candidate for PCa therapy following further investigation. In addition to regulating DNA damage repair, the MBTD1-containing TIP60 complex regulates the transcription/protein expression of the Myc proto-oncogene protein signaling pathway (11). Studies have suggested that Myc suppresses tumor invasion and cell migration by inhibiting c-Jun N-terminal kinase signaling (28). The present study demonstrated that the overexpression of MBTD1 positively correlated with distant metastasis and tumor invasion; whether it is associated with Myc pathway regulation remains to be explored.

In conclusion, the present study revealed that MBTD1 was overexpressed in PCa tissues and significantly correlated with advanced clinicopathological characteristics of PCa.
Furthermore, MBTD1 may act as a novel prognostic factor and diagnostic marker in $\mathrm{PCa}$.

\section{Acknowledgements}

Not applicable.

\section{Funding}

This work was supported by the National Natural Science Foundation of China (nos. 81472382 and 81672550); the Guangdong Province Natural Science Foundation (no. 2014A030313079); Guangdong Province Science and Technology for Social Development Project (no. 2017A020215018); Guangzhou Science and Technology Cooperation Program (Foreign research and development cooperation) (no. 201807010087); Guangzhou City in 2015 Scientific Research Project (no. 201510010298); International Science and Technology Cooperation Project of Guangdong Province Science and Technology Plan (no. 2016A050502020), Grant [2013]163 from the Key Laboratory of Malignant Tumor Molecular Mechanism and Translational Medicine of Guangzhou Bureau of Science and Information Technology and the Chinese National Scholarship to HH. National Natural Science Foundation of China (no. 81772733); Guangdong Province Science and Technology for Social Development Project (nos. 2014A020212018 and 2016A020215011); Guangzhou Science and Technology Plan (no. 201707010371) to ZHG 
and the National Natural Science Foundation of China for Young Scientists Grant (no. 81802527) to YML.

\section{Availability of data and materials}

All data generated during the presente study are included in this published article.

\section{Authors' contributions}

WHW and SMB were responsible for the study concept and design. DJZ and KWL acquired the tissue samples. WD and SMP conducted the immunohistochemistry analysis. YML and WH were responsible for the statistical analysis. QW, DJZ and KWL helped to perform the analysis and interpretation of data. HH, ZHG and LYL were involved in the design of the study, and the writing, review and revision of the manuscript. All authors read and approved the final manuscript.

\section{Ethics approval and consent to participate}

Ethical approval for this investigation was attained from the Research Ethics Committee, The Sun Yat-Sen Memorial Hospital, Sun Yat-Sen University (reference no. sysec-ky-ks-2018-011). Written informed consent was obtained from all participants at the time of original tissue collection.

\section{Patient consent for publication}

Not applicable.

\section{Competing interests}

The authors declare that they have no competing interests.

\section{References}

1. Dy GW, Gore JL, Forouzanfar MH, Naghavi $M$ and Fitzmaurice C: Global burden of urologic cancers, 1990-2013 Eur Urol 71: 437-446, 2017.

2. Fenner A: Prostate cancer: AS-contemplation, not intervention. Nat Rev Oncol 12: 595, 2015.

3. Tosoian JJ, Mamawala M, Epstein JI, Landis P, Wolf S, Trock BJ and Carter HB: Intermediate and longer-term outcomes from a prospective active-surveillance program for favorable-risk prostate cancer. J Clin Oncol 33: 3379-3385, 2016.

4. Attard G, Parker C, Eeles RA, Schröder F, Tomlins SA, Tannock I, Drake CG and de Bono JS: Prostate cancer. Lancet 387: 70-82, 2016.

5. Heidenreich A, Abrahamsson PA, Artibani W, Catto J, Montorsi F, Van Poppel H, Wirth M and Mottet N; European Association of Urology: Early detection of prostate cancer: European Association of Urology recommendation. Eur Urol 64: 347-354, 2013.

6. Center MM, Jemal A, Lortet-Tieulent J, Ward E, Ferlay J, Brawley $\mathrm{O}$ and Bray $\mathrm{F}$ : International variation in prostate cancer incidence and mortality rates. Eur Urol 61: 1079-1092, 2012.

7. Kattan MW, Vickers AJ, Yu C, Bianco FJ, Cronin AM, Eastham JA, Klein EA, Reuther AM, Edson Pontes J and Scardino PT: Preoperative and postoperative nomograms incorporating surgeon experience for clinically localized prostate cancer. Cancer 115: 1005-1010, 2009.

8. Mills AA: Throwing the cancer switch: Reciprocal roles of polycomb and trithorax proteins. Nat Rev Cancer 10: 669-682, 2010.

9. Eryilmaz J, Pan P, Amaya MF, Allali-Hassani A, Dong A, Adams-Cioaba MA, Mackenzie F, Vedadi M and Min J: Structural studies of a four-MBT repeat protein MBTD1. PLoS One 4: e7274, 2009.
10. Wismar J, Loffler T, Habtemichael N, Vef O, Geissen M, Zirwes R, Altmeyer W, Sass H and Gateff E: The Drosophila melanogaster tumor suppressor gene lethal(3)malignant brain tumor encodes a proline-rich protein with a novel zinc finger. Mech Dev 53: 141-154, 1995.

11. Jacquet K, Fradet-Turcotte A, Avvakumov N, Lambert JP, Roques C, Pandita RK, Paquet E, Herst P, Gingras AC, Pandita TK, et al: The TIP60 complex regulates bivalent chromatin recognition by 53BP1 through direct H4K20me binding and H2AK15 acetylation. Mol Cell 62: 409-421, 2016.

12. Dewaele B, Przybyl J, Quattrone A, Finalet Ferreiro J, Vanspauwen V, Geerdens E, Gianfelici V, Kalender Z, Wozniak A, Moerman P, et al: Identification of a novel, recurrent MBTD1-CXorf67 fusion in low-grade endometrial stromal sarcoma. Int J Cancer 134: 1112-1122, 2014.

13. de Rooij JD, van den Heuvel-Eibrink MM,Kollen WJ, Sonneveld E, Kaspers GJ, Beverloo HB, Fornerod M, Pieters R and Zwaan CM: Recurrent translocation $\mathrm{t}(10 ; 17)(\mathrm{p} 15 ; \mathrm{q} 21)$ in minimally differentiated acute myeloid leukemia results in ZMYND11/MBTD1 fusion. Genes Chromosomes Cancer 55: 237-241, 2016.

14. De Braekeleer E, Auffret R, Douet-Guilbert N, Basinko A, Le Bris MJ, Morel F and De Braekeleer M: Recurrent translocation $(10 ; 17)(\mathrm{p} 15 ; \mathrm{q} 21)$ in acute poorly differentiated myeloid leukemia likely results in ZMYND11-MBTD1 fusion. Leuk Lymphoma 55: 1189-1190, 2014.

15. Klymenko T, Papp B, Fischle W, Köcher T, Schelder M, Fritsch C, Wild B, Wilm M and Müller J: A Polycomb group protein complex with sequence-specific DNA-binding and selective methyl-lysine-binding activities. Genes Dev 20: 1110-1122, 2006.

16. Grimm C, de Ayala Alonso AG, Rybin V, Steuerwald U, Ly-Hartig N, Fischle W, Müller J and Müller CW: Structural and functional analyses of methyl-lysine binding by the malignant brain tumour repeat protein Sex comb on midleg. EMBO Rep 8: 1031-1037, 2007.

17. Chen X, Xie W, Gu P, Cai Q, Wang B, Xie Y, Dong W, He W, Zhong G, Lin T and Huang J: Upregulated WDR5 promotes proliferation, self-renewal and chemoresistance in bladder cancer via mediating H3K4 trimethylation. Sci Rep 5: 8293, 2015.

18. Ma X, Du T, Zhu D, Chen X, Lai Y, Wu W, Wang Q, Lin C, Li Z, Liu L and Huang H: High levels of glioma tumor suppressor candidate region gene 1 predicts a poor prognosis for prostate cancer. Oncol Lett 16: 6749-6755, 2018.

19. Cimino-Mathews A, Subhawong AP, Illei PB, Sharma R, Halushka MK, Vang R, Fetting JH, Park BH and Argani P: GATA3 expression in breast carcinoma: Utility in triple-negative, sarcomatoid, and metastatic carcinomas. Hum Pathol 44: 1341-1349, 2013.

20. Bachmann IM, Halvorsen OJ, Collett K, Stefansson IM, Straume O, Haukaas SA, Salvesen HB, Otte AP and Akslen LA: EZH2 expression is associated with high proliferation rate and aggressive tumor subgroups in cutaneous melanoma and cancers of the endometrium, prostate, and breast. J Clin Oncol 24: 268-273, 2006

21. Gu P, Chen X, Xie R, Han J, Xie W, Wang B, Dong W, Chen C, Yang M, Jiang J, et al: lncRNA HOXD-AS1 regulates proliferation and chemo-resistance of castration-resistant prostate cancer via recruiting WDR5. Mol Ther 25: 1959-1973, 2017.

22. Chen X, Gu P, Xie R, Han J, Liu H, Wang B, Xie W, Xie W, Zhong G, Chen C, et al: Heterogeneous nuclear ribonucleoprotein $\mathrm{K}$ is associated with poor prognosis and regulates proliferation and apoptosis in bladder cancer. J Cell Mol Med 21: 1266-1279, 2017.

23. Nady N, Krichevsky L, Zhong N, Duan S, Tempel W, Amaya MF, Ravichandran M and Arrowsmith CH: Histone recognition by human malignant brain tumor domains. J Mol Biol 423: 702-718, 2012.

24. Wang YQ, Wang PY, Wang YT, Yang GF, Zhang A and Miao ZH: An update on Poly(ADP-ribose)polymerase-1 (PARP-1) inhibitors: Opportunities and challenges in cancer therapy. J Med Chem 59: 9575-9598, 2016

25. Kluzek K, Bialkowska A, Koczorowska A and Zdzienicka MZ: Poly(ADP-ribose) polymerase (PARP) inhibitors in BRCA1/2 cancer therapy. Postepy Hig Med Dosw (Online) 66: 372-384, 2012.

26. Gao D, Herman JG and Guo M: The clinical value of aberrant epigenetic changes of DNA damage repair genes in human cancer. Oncotarget 7: 37331-37346, 2016.

27. Kirmizis A, Bartley SM and Farnham PJ: Identification of the polycomb group protein $\mathrm{SU}(\mathrm{Z}) 12$ as a potential molecular target for human cancer therapy. Mol Cancer Ther 2: 113-121, 2003.

28. Ma X, Huang J, Tian Y, Chen Y, Yang Y, Zhang X, Zhang F and Xue L: Myc suppresses tumor invasion and cell migration by inhibiting JNK signaling. Oncogene 36: 3159-3167, 2017. 